\title{
Neutronics integral experiments in iron assemblies
}

\author{
Liu Rong, Jiang Li, Zhu Chuanxin, and Chen Yuan \\ Institute of Nuclear Physics and Chemistry, China Academy of Engineering Physics, Mianyang 621900, P.R. China
}

\begin{abstract}
The paper describes recent progress in neutronics integral experiments in iron assemblies. The absolute activation reaction rates in an iron sphere were measured by eight kinds of activation foils. The absolute activation reaction rates at an end of iron cylinders with different thickness were measured by a set of activation foils. The leakage $\gamma$-ray spectra from the iron spheres were measured with a BC-501A scintillation spectrometer. The measured results are compared to the calculated ones.
\end{abstract}

\section{Introduction}

The fusion reactor is one of most promising clean sources. The blanket of fusion reactor is used for shielding D-T neutrons, producing tritium, etc. Neutrons produced by D-T fusion reactions are to activate the first wall and structural materials. The check of the prediction capabilities of the nuclear performance of ITER First wall/Blanket/Shield system is very important in the design stage. Iron is a structural material of a fusion reactor, such as ITER. It has an important role of shielding radiation. For checking nuclear data of iron, it is necessary to carry out neutronics integral experiments in iron assemblies. Recently, several neutronics integral experiments in iron assemblies have been performed in INPC. The paper describes progress in the experiments [1-3].

\section{Measurements of absolute activation reaction rates in an iron sphere}

The reaction rates were measured by using a set of activation foils with different reaction energy thresholds. These activation foils were placed along the radial direction of a sphere, and irradiated with a D-T fusion neutron source which was located at the centre of the sphere. The gamma activities of the activated foils were measured with a high-purity germanium (HPGe) gamma spectrometer, and then corrected to obtain the absolute reaction rates.

The Fe sphere was $3.1 / 35 \mathrm{~cm}$ in IR/OR, consisted of four spherical shells with $3.1 / 8.1,8.1 / 18.1,18.1 / 29.5,29.5 / 35 \mathrm{~cm}$ in IR/OR. The schematic diagram of the Fe sphere with activation foil detectors is shown in figure 1 .

The activation foils were $18 \mathrm{~mm}$ in diameter, $0.1 \sim 0.5 \mathrm{~mm}$ in thickness. The activation reactions of foils with its energy thresholds shown in bracket are as follows: ${ }^{55} \mathrm{Mn}(\mathrm{n}, \gamma)^{56} \mathrm{Mn}$ (thermal-neutron), ${ }^{115} \operatorname{In}\left(\mathrm{n}, \mathrm{n}^{\prime} \gamma\right){ }^{115 \mathrm{~m}} \mathrm{In} \quad(1.2 \mathrm{MeV}),{ }^{58} \mathrm{Ni}(\mathrm{n}, \mathrm{p})$ ${ }^{58} \mathrm{Co}(2.8 \mathrm{MeV}),{ }^{64} \mathrm{Zn}(\mathrm{n}, \mathrm{p}){ }^{64} \mathrm{Cu} \quad(2.8 \mathrm{MeV}),{ }^{56} \mathrm{Fe}(\mathrm{n}, \mathrm{p}){ }^{56} \mathrm{Mn}$ (6.3 MeV), ${ }^{24} \mathrm{Mg}(\mathrm{n}, \mathrm{p}){ }^{24} \mathrm{Na} \quad(7.0 \mathrm{MeV}),{ }^{27} \mathrm{Al}(\mathrm{n}, \alpha){ }^{24} \mathrm{Na} \quad(7.2$ $\mathrm{MeV}),{ }^{93} \mathrm{Nb}(\mathrm{n}, 2 \mathrm{n}){ }^{92 \mathrm{~m}} \mathrm{Nb} \quad(9.0 \mathrm{MeV})$ and ${ }^{63} \mathrm{Cu}(\mathrm{n}, 2 \mathrm{n}){ }^{62} \mathrm{Cu}$ $(12.6 \mathrm{MeV})$. The absolute activation reaction rates in $\mathrm{Fe}$ were measured by eight kinds of foils of $\mathrm{Mn}, \mathrm{In}, \mathrm{Zn}, \mathrm{Ni}, \mathrm{Fe}, \mathrm{Mg}, \mathrm{Al}$

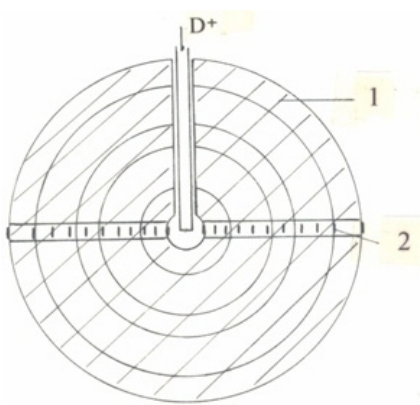

Fig. 1. Schematic diagram of iron sphere shell, 1-iron sphere; 2- activation foil.
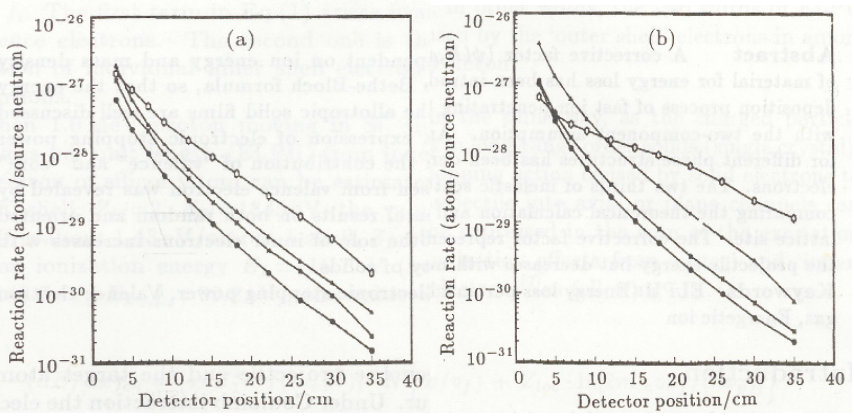

Fig. 2. Distributions of absolute reaction rates in Fe obtained, respectively, with $\mathrm{In}(\mathrm{\circ}), \mathrm{Zn}(\mathbf{\Delta}), \mathrm{Al}(\bullet)$ and $\mathrm{Cu}(\times)$ foils (in figure $2 \mathrm{a}$ ); $\mathrm{Mn}$ $(\circ), \mathrm{Ni}(\boldsymbol{\Delta}), \mathrm{Fe}(\bullet)$ and $\mathrm{Mg}(\times)$ foils (in figure $2 \mathrm{~b}$ ).

and $\mathrm{Cu}$. The distributions of the reaction rates in radial channel are shown in figure 2.

In the experiments, the intensity of the D-T neutron source was about $1 \times 10^{10}(\mathrm{n} / \mathrm{s})$. The fraction of D-D neutrons was less than $1 \%$. The efficiencies of the HPGe detector were calibrated by ${ }^{152} \mathrm{Eu},{ }^{137} \mathrm{Cs}$ and ${ }^{241} \mathrm{Am}$ gamma plane sources with $18 \mathrm{~mm}$ in diameter.

The gamma spectra from different activation foils were measured in the same condition. When peak area corresponding to the characteristic gamma-ray energy was calculated, the effects of background, interfering reactions, dead time, etc., were considered in detail. The measured results of reaction rates were normalized to one foil atom and one source neutron. The total experimental error is about 5\% 7\%. The 
measured results are compared to the values calculated with the 1-D ANISN code and ENDF/B-VI library data. There exist differences to different extents between the measured and calculated results in $\mathrm{Fe}$, average $\mathrm{E} / \mathrm{C}$ about $5 \% \sim 30 \%$. Further analysis is needed.

\section{Measurements of absolute activation rates at ends of iron cylinders}

The iron cylinders were 5, 10, 15, 20 and $25 \mathrm{~cm}$ in thickness, respectively, and $20 \mathrm{~cm}$ in diameter. The D-T neutron source was $10 \mathrm{~cm}$ away from an end of iron cylinders. A set of activation foils was put at another end of iron cylinders. The foil was set on the centre of the end of the iron cylinder. The activation foils are ${ }^{56} \mathrm{Fe},{ }^{27} \mathrm{Al},{ }^{19} \mathrm{~F}$, and ${ }^{90} \mathrm{Zr}$ which are the same as the ones described above. The schematic diagram is shown in figure 3 .

The distributions of reaction rates at the centre of the ends of cylinders with change of thicknesses are shown in figure 4 . The total experimental error is about $5.3 \% \sim 6.5 \%$.

From figure 4 , the activation reaction rates have exponential change with the thicknesses. The distribution of reaction rates is consistent with the ones of the reaction cross sections of foils. The measured results are compared to the values calculated with the MCNP4A code and FENDL-2 for F, Fe and $\mathrm{Al}$ foils, ENDF/B-VI for $\mathrm{Zr}$ foils. There exists differences to different extents between the measured and calculated results on ends of iron cylinders, the average $\mathrm{E} / \mathrm{C}$ is about $14 \%$

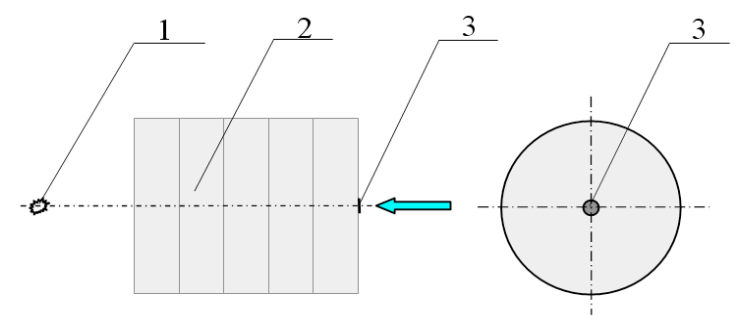

Fig. 3. Schematic diagram of iron cylinders, 1-D-T neutron source; 2-iron cylinder; 3 -activation foil.

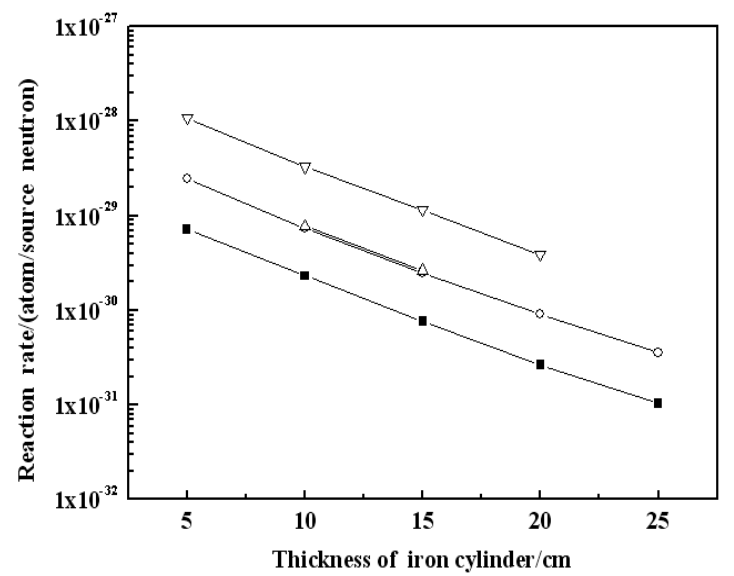

Fig. 4. The distributions of reaction rates with change of thickness, respectively, with $\mathrm{F}(\mathbf{\square}), \mathrm{Fe}(\circ), \mathrm{Al}(\Delta)$ and $\mathrm{Zr}(\nabla)$ foils.

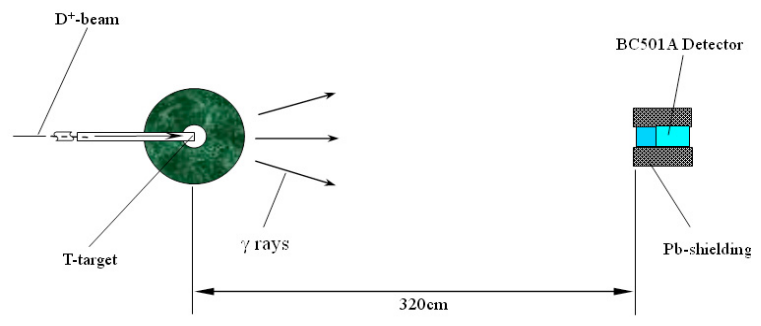

Fig. 5. Experimental assembly.

$\sim 21 \%$ for $\mathrm{F}$ foils, about $3 \% \sim 7 \%$ for $\mathrm{Fe}$ and $\mathrm{Zr}$ foils, about $1 \%$ for $\mathrm{Al}$ foils. Further analysis is needed.

\section{Measurements of leakage $\gamma$-ray spectra from iron spheres}

The $\gamma$-ray spectrometer was a $\Phi 5.08 \mathrm{~cm} \times \mathrm{L} 5.08 \mathrm{~cm}$ $\mathrm{BC}-501 \mathrm{~A}$ liquid scintillation spectrometer. The response function of monoenergitic $\gamma$-rays was calculated by MARTHA Monte Carlo program. The D-T neutron source was at the entrance of the iron sphere. The inner diameter of the sphere was $4 \mathrm{~cm}$. The outer diameters were $12,16,26,36$ and $47.6 \mathrm{~cm}$, respectively. The distance of the detector to a neutron source is $320 \mathrm{~cm}$. The $\gamma$ rays background was deducted. The experiment assembly is shown in figure 5. The measured $\gamma$-ray spectra from a series of iron spheres are shown in figure 6 .

The leakage $\gamma$-ray spectra are calculated by MCNP4A with FENDL-2, ENDF/B-VI, t-2 and ENDF/B-V. For different
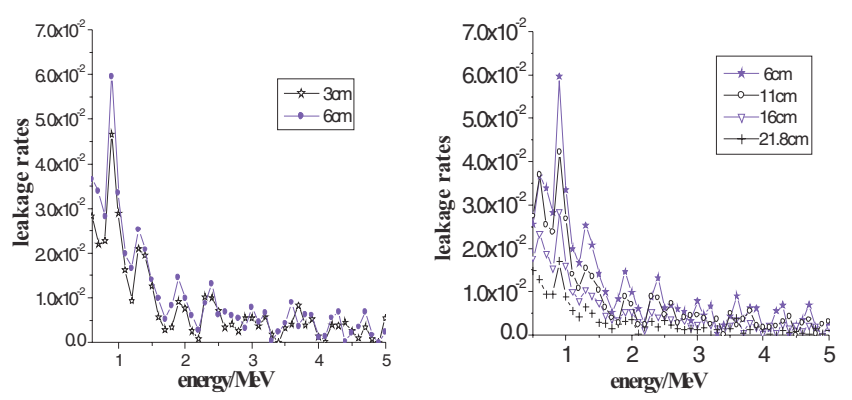

Fig. 6. Measured $\gamma$-ray spectra from iron spheres.

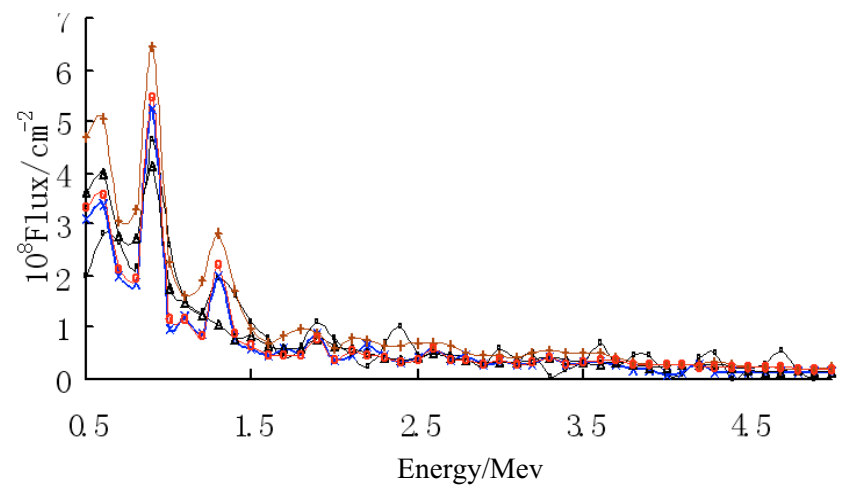

Fig. 7. Comparison of calculations with different data library and experiments, respectively, with $\square$-Exp.; $\times$-t-2; $\triangle$-FENDL2; +-ENDF/B$\mathrm{V} ;$ o-ENDF/B-VI. 
library, $\mathrm{E} / \mathrm{C}$ of leakage rates is $1.05,1.10,1.18$ and 0.77 , respectively. The comparison of calculations with different data library and experiments is shown figure 7.

From figure 6, when the thickness of the spheres is less than $6 \mathrm{~cm}, \gamma$-ray leakage rates increase with the increasing of thickness. When the thickness of the spheres is larger than $6 \mathrm{~cm}, \gamma$-ray leakage rates decrease with the increasing of thickness. The total experimental error is $4 \% \sim 6 \%$.

\section{Conclusions}

Several neutronics integral experiments in iron assemblies have been performed. Absolute activation reaction rates, gamma spectra in the assemblies were measured. The measured results are compared to the calculated ones. Theexperimental results are very significant to check nuclear data of iron and design the blanket in a fusion reactor. For improving data library evaluated, it is necessary to check nuclear data by integral benchmark experiments.

\section{References}

1. R. Liu et al., Nucl. Sci. Tech. 9, 82 (1998).

2. L. Jiang et al. (2006) (private communication).

3. C.X. Zhu et al., At. Energy Sci. Technol. 38, 294 (2004). 